\title{
Lipid profile and socioeconomic status in healthy middle aged women in Sweden
}

\author{
Sarah Prossie Wamala, Alicia Wolk, Karin Schenck-Gustafsson, Kristina Orth-Gomér
}

\begin{abstract}
Study objective-To examine the relationship between socioeconomic status (SES) and full lipid profile in middle aged healthy women.
\end{abstract}

Participants-These comprised 300

healthy Swedish women between 30 and 65 years who constitute the control group of the Stockholm female coronary risk study, a population based, case-control study of women with coronary heart disease (CHD). The age matched control group, drawn from the census register of greater Stockholm, was representative of healthy Swedish women aged $30-65$ years. Five measures of SES were used; educational level, occupation, decision latitude at work, annual income, and size of house or apartment.

Main results-Swedish women with low decision latitude at work, low income, low educational level, blue collar jobs, and who were living in small houses or apartments had an unhealthy lipid profile, suggesting an increased risk of CHD. Part of this social gradient in lipids was explained by an unhealthy lifestyle, but the lipid gradients associated with decision latitude at work and annual income were independent of these factors. Decision latitude, educational level, and annual income had the strongest associations with lipid profile. These associations were independent of age, menopausal status, smoking, sedentary lifestyle, alcohol consumption, obesity, excess abdominal fat, and unhealthy dietary habits. Of the lipid variables, low high density lipoprotein cholesterol (HDL) levels were most consistently associated with low SES.

Conclusions-Decision latitude at work was the strongest SES predictor of HDL levels in healthy middle aged Swedish women, after simultaneous adjustment for other SES measures, age, and all lifestyle factors in the multivariable regression model.

\section{(f Epidemiol Community Health 1997;51:400-407)}

Several studies have shown a strong relationship between socioeconomic status (SES) and coronary heart disease (CHD). A social gradient in CHD morbidity and mortality, with an increase from upper to lower social classes, has been reported from the United Kingdom, the United States, Sweden, and most other industrialised countries. ${ }^{1-9}$
Among the principal markers of increased risk of CHD are raised serum lipid concentrations. Whether these are related to social class differences in general is not known, but several studies have shown an association between education and total as well as high density lipoprotein (HDL)cholesterol in men and women. ${ }^{10-14}$ These studies have neither considered the full lipid profile nor various measures of SES and their relevance for both men and women.

In view of its association with many other risk factors, epidemiologists frequently consider social class as a potentially confounding variable. Social class in itself cannot be understood as a cause of disease, but perhaps as a proxy measure of social strain or social deprivation. The concept of social class has its origin in political sciences. According to Max Weber, a German sociologist and political scientist, social class is based on three main dimensions: "class", "status", and "power". ${ }^{15}$ Weber associated "class" with ownership such as housing and income, "status" with lifestyle and social prestige (education and occupation), and "power" with the means to make decisions (decision latitude). Most measures of SES developed by sociologists, are based on Weber's view of these three separate, but linked, dimensions of social class.

In men, occupational grade is frequently used as a comprehensive measure of SES. Most social classifications using occupational grade were developed on the basis of the male labour force. In women, the validity of this measure as a social determinant can be questioned.

A large proportion of women in Sweden are employed outside their home $(76 \%)$, but female employment categories show little variety, and most women are found within a narrow range of occupations. Therefore occupational grade may not be a good enough indicator of SES in women. ${ }^{16}$

This report examines the relationship between a set of social class indicators and the full lipid profile in women. Social class indicators, according to Weber's definition, were education and occupation classified as white or blue collar ("social status"), decision latitude at work ("power"), annual income and housing conditions ("social class")

\section{Methods}

The study group comprised 300 healthy women aged $30-65$ years. They constitute the control group of the Stockholm FemCorRisk study, which is a population based case control study of psychosocial and biological risk factors 
for CHD in women. All female cases, 65 years of age or younger admitted to hospital in greater Stockholm for an acute CHD event between February 1991 and May 1994 were included. A detailed description of the study group is given elsewhere. ${ }^{17}$

Control subjects were obtained from the census register of greater Stockholm. This population register includes the person identification number (based on birth date and gender) of the residents in Stockholm. Therefore, identification of closely age matched control subjects was possible. For each case, a healthy woman, born on the same day or another day as close as possible, was chosen. "Healthy" was defined as being free from symptoms of heart disease, and without hospitalisation for any illness during the prior five year period.

The control subjects were compared for health related factors with a random sample of 2500 women of the same age from the general Stockholm population. No differences in educational level or health behaviours (smoking, exercise, and dietary habits) were found. ${ }^{18} \mathrm{Al}-$ though older women are over represented due to the study design, the study group can be regarded as representative of healthy women aged 30-65 years in the normal Swedish population.

The subjects were contacted by a letter. This explained the objectives and the focus of the study and invited them to participate. Those who did not call the clinic spontaneously were then contacted by phone. Altogether $17 \%$ declined to participate, mainly due to difficulties in arranging time off from work to participate in the study.

\section{MEASURES OF SES}

For this report, educational level was categorised as follows: $I=$ graduate professional training, eg Masters degree, PhD degree (corresponding to $18-20$ years of school education); II =standard college or university degree, eg Bachelors degree (corresponding to $16-17$ years of school education); III $=$ partial training, completed at least one year (corresponding to 13-15 years of school education); IV = high school graduate (corresponding to 12 years of school education); $\mathrm{V}=$ partial high school (corresponding to 10 or 11 years of school education); VI = junior high school (corresponding to 7, 8, or 9 years); and $\mathrm{VII}=$ fewer than 7 years of school education .

Occupational level was based on the question: "What is your current occupation? If no longer employed, state your last job". Since occupation is a complex SES indicator, further questions were asked, concerning the kind of business, employer (public sector, private sector, family business or own business), and length of employment. If a woman was out of work at the time, her previous job was considered for occupational classification. Thirty five women were 65 years old and were retired. Twenty further women were unemployed, studying, or had taken early retirement. One woman who had been a housewife for her entire adult life and was excluded from the analyses.

\section{KEY POINTS}

- There was a strong social gradient in serum lipid concentrations in women.

- HDL concentrations were most consistently associated with low socioeconomic status.

- Low decision latitude at work was the strongest independent determinant of low HDL concentrations.

In summary, 56 women were not actually working at the time of examination, but their previous jobs enabled categorisation of occupation.

In this sample the actual employment rate was $81 \%$, which is similar to the female employment rate (79\%) in greater Stockholm during the study period. ${ }^{19}$

Occupation was divided into blue collar and white collar.

Decision latitude at work according to $\mathrm{Ka}-$ rasek et al was used. ${ }^{20}$ Decision latitude refers to the control and power which one has at work, and describes a person's ability to control her/his own work activities. The scale included six well validated questions (scores ranging from 1-24) on intellectual discretion and authority to make decisions on how and what to do in one's job. Subjects were asked questions whether their job:

- Required them to learn new things,

- Was not monotonous,

- Required creativity,

- Required a high level of skills,

- Gave them a lot of say on the job, and

- Allowed them to take part in decisions that affected their work.

The subjects were given four alternative answers (strongly disagree, disagree, agree, or strongly agree), the highest score (positive answer) corresponding to high decision latitude.

Size of house/apartment was expressed as number of rooms, excluding the kitchen. Annual income was obtained from the government register of taxation using the public database of the taxation office. For all women who were examined between 1991 and 1992, the annual income for 1990 was considered, while for those who were examined between 1993 and 1994, the annual income for 1991 was considered.

In this report, "power" is reflected by the decision latitude at work, "status" is reflected by the educational level and by the occupation (classified as blue or white collar), and "class" by the number of rooms in the house or apartment and by the annual income.

\section{LIPID VARIABLES (OUTCOME VARIABLES)}

Venous blood samples were drawn from the right arm of each subject into serum separated tubes, which were centrifuged for 10 minutes at $3000 \mathrm{~g}$. Four $\mathrm{ml}$ samples of plasma was obtained and frozen to $-70^{\circ} \mathrm{C}$. They were sent in batches to the processing laboratory (CALAB) once per month. Tubes were iden- 
tified by number only, and laboratory personnel were blinded as to case or control status. Each batch contained samples from both cases and controls, in random order.

Total cholesterol was determined with CHOD-PAP and triglycerides with GPD-PAP enzymatic methods with reagents from Boehringer Mannheim (Germany). High density lipoproteins were determined based on the isolation of LDL and VLDL from serum by precipitation. The cholesterol content of the supernatant, ie HDL cholesterol, was measured enzymatically. ${ }^{21}$

Serum apolipoprotein A1 and apolipoprotein B were measured by immunoturbidometry according to Riepponen et al, using polyclonal antisera (Orion Diagnostics). ${ }^{22}$ All measurements were carried out in the same laboratory (CALAB), using an automated multichannel analyser. ${ }^{23}$

\section{COVARIATES}

Age, marital status, number of persons in the household, smoking behaviour, menopausal status, and physical exercise were assessed by interviews and questionnaires.

Marital status was categorised as single, widowed, divorced, or cohabiting.

Subjects were defined as cohabiting if they reported being married or living with a male partner, and defined as single if they reported living alone. In this sample, 166 women were actually married and 22 women were unmarried, but living with a male partner. Menopausal status was categorised into three categories; premenopausal, postmenopausal with hormone replacement, and postmenopausal without hormone replacement.

\section{LIFESTYLE FACTORS}

Smoking behaviour was dichotomised as: $0=$ never smoked or previously smoked (more than a year before the study) and $1=$ currently smoking including those who had quit within a year from the start of the study.

Leisure time physical activity was assessed according to the World Health Organization criteria, and graded I to IV; I = reading, watching television or other sedentary leisure activities, II = walking, cycling or other forms of physical activity, III=exercises to keep fit, heavy gardening, etc., for at least four hours a week, IV = hard training or participation in competitive sports regularly, several times per week. In the analyses, physical activity in leisure time was dichotomised into sedentary (I) and non sedentary (II-IV).

Weight, height, and waist and hip circumference were measured by a specially trained research nurse during examination. Waist circumference was measured as the most narrow part around the waist line. Hip circumference was measured at the widest point between the umbilicus and thighs. All measurements of circumference were taken to the nearest $0.5 \mathrm{~cm}$. Body mass index (BMI) was calculated as weight $(\mathrm{kg})$ divided by height $\left(\mathrm{m}^{2}\right)$, and the waist-hip ratio as waist/hip circumference.

\section{DIETARY HABITS}

Variables describing dietary habits included total energy, total fat, carbohydrate and protein intake. Diet was assessed using an 88-food item frequency questionnaire (FFQ) with relative portion sizes. ${ }^{24}$

For foods usually eaten on a daily basis such as milk ( 5 types), bread ( 4 types), cheese ( 6 types), coffee, sugar and fat on sandwiches, open questions about number of glasses of milk, slices of bread, slices of cheese, cups of coffee, teaspoons of sugar per day or week were asked. For fat on sandwiches, the participants were asked whether they usually used a thick or a thin layer. For the other 58 food items listed in the questionnaire, participants were asked to estimate frequency of consumption and indicate what portion size they usually ate (small, medium, large) in relation to specified standard portions for each food item. These standard portions correspond to "natural" units (eg, one orange, two eggs) or typical serving size, derived from "Weight tables for foods and dishes" prepared by the Swedish Food Administration. ${ }^{25}$ In the FFQ there were nine predefined frequency categories, ranging from "never or less than once per month" to "three or more times per day".

The questionnaire also included additional questions about type of fat on the table ( 5 types), fat usually used in cooking (8 types), portion of visible fat from meat and part of skin from chicken/poultry usually consumed ("all", "only a part", "as much fat/skin removed as possible").

Daily energy and nutrient intake were calculated by multiplying the frequency of use of each food by the indicated portion size and by the nutrient content of each food item (or a weighted average nutrient composition of each food group), and then summing across all foods. The nutrient composition data used for calculations was derived from the Swedish Food Administration food data base PC Version $1992 .{ }^{26}$ For nutrient calculations, missing frequency answers were treated as "never or less than once per month" category.

Information about consumption of five alcoholic beverages (beer $2.8 \%$ alcohol, beer $4.5 \%$, wine $10-15 \%$, sherry $20 \%$, spirits $40 \%$ ) was obtained by open ended questions about frequency per year, per month, per week, and per day and about the usual number of specified servings (bottles, cans, glasses) consumed at each occasion.

The total average amount of alcohol $(100 \%$ ethanol) consumed was calculated in g/day taking into account frequency, amount, and content of alcohol in specific beverages. ${ }^{27}$ The FFQ was validated prior to the main study in a group of 184 women (mean age 52 years) who weighed and recorded all food eaten during 4, one week periods within one year. Mean total fat intake in the validation study was $65 \mathrm{~g} /$ day, based on food records and $47 \mathrm{~g} /$ day based on 
Table 1 Distribution of covariates and lipid variables $(n=300)$

\begin{tabular}{|c|c|c|}
\hline Variable & No (\%) & \\
\hline $\begin{array}{l}\text { Age } \\
\text { Decision latitude (score) } \\
\text { No of rooms in household } \\
\text { Body mass index (weight/height }{ }^{2} \\
\text { Waist-hip ratio } \\
\text { Alcohol consumption (g/d) } \\
\text { Total energy (KJ) } \\
\text { Total fat (g) } \\
\text { Carbohydrate (g) } \\
\text { Protein (g) } \\
\text { Total cholesterol (mmol/) } \\
\text { Serum-triglycerides (mmol/) } \\
\text { Serum-HDL cholesterol (mmol/l) } \\
\text { Serum-LDL cholesterol (mmol/l) } \\
\text { Cholesterol/HDL ratio } \\
\text { LDL/HDL ratio } \\
\text { Apolipoprotein B/apolipoprotein Al ratio }\end{array}$ & $\begin{array}{c}31(11) \\
24(8) \\
52(18) \\
188(63) \\
98(33) \\
55(18) \\
89(30) \\
153(51) \\
58(19) \\
\text { Mean (SD) } \\
56.4(7.1) \\
18,3(3,3) \\
410(1,7) \\
25.6(4.8) \\
0.80(0.09) \\
7.71(8.12) \\
1355,4(416,6) \\
47.9(19.7) \\
159.4(51.8) \\
58.3(17.7) \\
6.06(1.07) \\
1.06(0.55) \\
1.76(0.45) \\
3.81(1.01) \\
3.66(1.42) \\
2.34(0.97) \\
0.80(0.25)\end{array}$ & $\begin{array}{c}\text { Range } \\
30,65 \\
7,24 \\
1,11 \\
17.6,48.6 \\
0.53,1.44 \\
0.03,44.76 \\
507.2,2740.4 \\
13.2,131.2 \\
53.0,316.8 \\
19.9,130.9 \\
3.0,10.60 \\
0.30,4.20 \\
0.83,3.34 \\
0.80,7.60 \\
1.60,8.82 \\
0.43,6.99 \\
0.28,1.88\end{array}$ \\
\hline
\end{tabular}

the FFQ. Although, the FFQ underestimates an absolute average intake of total fat, it is a valid instrument for ranking of women, ie for an estimation of their relative fat intake. The Pearson correlation coefficient between 28 weighed food records and the FFQ for total fat intake was $r=0.60$ (Wolk, unpublished data).

\section{STATISTICAL ANALYSES}

The distributions of study variables were calculated for the whole study population. Means, standard deviations, and proportions were obtained.

Normality test for the distributions of lipid variables were conducted, using the ShapiroWilk test for normality. Triglycerides, HDL, LDL/HDL ratio, cholesterol/HDL ratio, and apolipoprotein B/apolipoprotein AI ratio had skewed distributions, therefore these variables were $\log$ transformed in the analyses. Only cholesterol had a normal distribution. In the multivariable analyses, the analysis of covariance technique, using standard least squares method, was performed by regressing lipid variables on each ordinal SES measure adjusting for age, menopausal status, marital status, number of persons in household, and lifestyle factors (smoking, physical activity, body mass index and waist/hip ratio, alcohol consumption, total energy, total fat, carbohydrate, and protein intake). Adjusted (least squares) means were calculated for each level of the ordinal SES measure.

In all analyses, lipid variables were treated as continuous, dependent variables and SES measures as independent variables with multiple classifications. Educational level and occupation were treated as categorical independent variables.

Annual income, number of rooms, and decision latitude were divided into quartiles based upon the distributions in the study group.
Age, body mass index, waist-hip ratio, alcohol consumption, and dietary variables were treated as continuous covariates. Physical activity and smoking were dichotomised, whereas, marital status and menopausal status were discrete variables in all analyses.

All statistical tests were two tailed. $\mathscr{F M P}$ Statistics for the Apple Macintosh Version 3.1 was used to run the analyses. ${ }^{28}$

\section{Results}

The distributions of the covariates and lipid profile are shown in table 1 . Age ranged from 30 to 65 years, with a mean of 56.4 (7.1) and a median of 58 years. The proportions of women in various SES categories (educational classes, occupations, decision latitude at work, housing, and annual income) are shown in tables 2 and 3.

Lifestyle factors were strongly associated with SES measures. A large proportion of women with low SES were smokers, had a sedentary lifestyle, were obese, had excess abdominal fat, and had unhealthy dietary habits. In contrast, high SES was associated with consumption of large quantities of alcohol. Unhealthy lifestyle was associated with a poor lipid profile.

\section{LIPID PROFILE IN RELATION TO EDUCATIONAI} LEVEL

For all lipid variables, women in the lowest educational strata had unhealthy lipid levels compared with those in the highest strata.

The analysis of variance showed significant differences across educational levels on HDL $(p=0.01)$, cholesterol/HDL ratio $(p=0.003)$, LDL/HDL ratio $(p=0.003)$ and the apolipoprotein $B /$ apolipoprotein $A 1$ ratio $(p=0.04)$ after adjusting for age. These associations persisted after further controlling for menopausal status. The effect on cholesterol and triglycerides levels did not reach statistical significance.

Low educational level was associated with old age $(p=0.001)$, smoking $(p=0.01)$, obesity $(p=0.01)$, abdominal fat $(p=0.004)$, and low alcohol consumption $(p=0.01)$.

After adjustment for smoking, physical activity, body mass index, and waist/hip ratio, alcohol consumption, total energy, total fat, carbohydrate and protein intake, significant associations remained only with $\mathrm{HDL}(\mathrm{p}=$ 0.04) (table 2).

\section{LIPID PROFILE IN RELATION TO OCCUPATION} (WHITE COLLAR V BLUE COLLAR)

After adjusting for age, women with blue collar jobs had a tendency towards lower levels of HDL $(p=0.07)$ and significantly raised cholesterol/HDL ratio $(p=0.04)$ and $L D L / H D L$ ratio $(p=0.04)$. These associations were not affected by the additional adjustment for menopausal status, but disappeared when adjusting for lifestyle factors. Women with blue collar jobs were more likely to be obese $(p=0.03)$ and to have excess abdominal fat $(p=0.01)$. 
Table 2 Effect of educational level on lipid profile. Mean (SEM) lipid values

\begin{tabular}{|c|c|c|c|c|c|c|c|}
\hline $\begin{array}{l}\text { Educational } \\
\text { level }\end{array}$ & No & $\begin{array}{l}\text { Cholesterol } \\
(\mathrm{mmol} / \mathrm{l})\end{array}$ & $\begin{array}{l}\text { Triglycerides } \\
(\mathrm{mmol} / \mathrm{l})\end{array}$ & $\begin{array}{l}H D L \\
(\mathrm{mmol} / \mathrm{l})\end{array}$ & $\begin{array}{l}\text { Cholesterol/ } \\
H D L\end{array}$ & $L D L / H D L$ & $\begin{array}{l}\text { Apolipoprotein B/ } \\
\text { apolipoprotein } A 1\end{array}$ \\
\hline \multicolumn{8}{|c|}{ Adjusted for age: } \\
\hline I (lowest) & 35 & $5.83(0.17)$ & $1.01(0.09)$ & $1.96(0.08)$ & $3.26(0.19)$ & $2.0(0.16)$ & $0.73(0.04)$ \\
\hline II & 46 & $5.91(0.14)$ & $0.94(0.08)$ & $1.82(0.07)$ & $3.45(0.16)$ & $2.17(0.14)$ & $0.76(0.04)$ \\
\hline III & 33 & $5.95(0.25)$ & $1.04(0.09)$ & $1.78(0.08)$ & $3.41(0.19)$ & $2.12(0.16)$ & $0.73(0.04)$ \\
\hline IV & 28 & $6.05(0.19)$ & $1.20(0.10)$ & $1.64(0.08)$ & $3.99(0.21)$ & $2.61(0.18)$ & $0.86(0.05)$ \\
\hline V & 18 & $6.0 \quad(0.13)$ & $0.94(0.14)$ & $1.92(0.11)$ & $3.22(0.28)$ & $1.98(0.24)$ & $0.76(0.06)$ \\
\hline VI & 59 & $6.11(0.17)$ & $1.06(0.07)$ & $1.74(0.06)$ & $3.67(0.15)$ & $2.34(0.13)$ & $0.79(0.03)$ \\
\hline VII (highest) & 81 & $6.25(0.11)$ & $1.14(0.06)$ & $1.66(0.05)$ & $4.04(0.13)$ & $2.67(0.11)$ & $0.87(0.03)$ \\
\hline Difference* & & 0.44 & 0.13 & 0.30 & 0.78 & 0.67 & 0.14 \\
\hline \multicolumn{2}{|c|}{$\begin{array}{l}\text { p† } \\
\text { Adjusted for age and lifestyle factorsł: }\end{array}$} & 0.33 & 0.09 & 0.01 & 0.003 & 0.005 & 0.04 \\
\hline \multicolumn{2}{|c|}{ p† } & 0.35 & 0.11 & 0.04 & 0.08 & 0.11 & 0.31 \\
\hline
\end{tabular}

* Difference in adjusted mean values between the two extreme classes (I and VII).

$t p=p$ value for the differences in lipid levels across educational levels.

¥Lifestyle factors include smoking, physical exercise, alcohol consumption, total energy, total fat, carbohydrate, protein intake, body mass index and waist/hip ratio.

Table 3 Effect of occupation on lipid profile. Mean (SEM) lipid values

\begin{tabular}{|c|c|c|c|c|c|c|c|}
\hline $\begin{array}{l}\text { Occupational } \\
\text { category }\end{array}$ & No & $\begin{array}{l}\text { Cholesterol } \\
\text { (mmol/l) }\end{array}$ & $\begin{array}{l}\text { Triglycerides } \\
\text { (mmolll) }\end{array}$ & $\begin{array}{l}\text { HDL } \\
(\mathrm{mmol} / \mathrm{l})\end{array}$ & Cholesterol/HDL & $L D L / H D L$ & $\begin{array}{l}\text { Apolipoprotein } B / \\
\text { apolipoprotein } A 1\end{array}$ \\
\hline \multicolumn{8}{|c|}{ Adjusted for age: } \\
\hline Blue collar & 64 & $6.14(0.12)$ & $1.11(0.07)$ & $1.69(0.06)$ & $3.93(0.14)$ & $2.58(0.12)$ & $0.84(0.03)$ \\
\hline White collar & 233 & $6.03(0.06)$ & $1.04(0.04)$ & $1.78(0.03)$ & $3.57(0.07)$ & $2.27(0.06)$ & $0.78(0.02)$ \\
\hline Difference* & & 0.11 & 0.07 & 0.09 & 0.36 & 0.31 & 0.06 \\
\hline \multicolumn{2}{|c|}{$\begin{array}{l}\mathrm{p} \dagger \\
\text { Adjusted for age and lifestyle factorsł: }\end{array}$} & 0.40 & 0.37 & 0.07 & 0.04 & 0.04 & 0.09 \\
\hline p† & ctorsf: & 0.42 & 0.78 & 0.23 & 0.17 & 0.18 & 0.63 \\
\hline
\end{tabular}

* Difference $=$ difference in mean values between blue collar and white collar jobs.

$t p=p$ value for the effect of occupational category on lipid variables.

$\ddagger$ Lifestyle factors include smoking, physical exercise, alcohol consumption, total energy, total fat, carbohydrate, protein intake, body mass index and waist/hip ratio.

Table 4 Effect of decision latitude on lipid profile. Mean (SEM) lipid values

\begin{tabular}{|c|c|c|c|c|c|c|c|c|}
\hline $\begin{array}{l}\text { Decision latitude } \\
\text { (quartiles) }\end{array}$ & $\begin{array}{l}\text { Range in } \\
\text { scores }\end{array}$ & No & $\begin{array}{l}\text { Cholesterol } \\
\text { (mmolll) }\end{array}$ & $\begin{array}{l}\text { Triglycerides } \\
\text { (mmolll) }\end{array}$ & $\begin{array}{l}H D L \\
(\text { mmolll })\end{array}$ & $\begin{array}{l}\text { Cholesteroll } \\
\text { HDL }\end{array}$ & $L D L / H D L$ & $\begin{array}{l}\text { Apolipoprotein BI } \\
\text { apolipoprotein } A 1\end{array}$ \\
\hline \multicolumn{9}{|l|}{ Adjusted for age: } \\
\hline I (lowest) & $6-16$ & 63 & $6.09(0.14)$ & $1.10(0.06)$ & $1.58(0.05)$ & $3.82(0.14)$ & $2.44(0.12)$ & $0.82(0.03)$ \\
\hline II & $18-19$ & 45 & $6.11(0.13)$ & $0.98(0.07)$ & $1.70(0.06)$ & $3.76(0.16)$ & $2.47(0.14)$ & $0.83(0.04)$ \\
\hline III & & 56 & $5.77(0.12)$ & $1.03(0.07)$ & $1.86(0.06)$ & $3.49(0.14)$ & $2.19(0.12)$ & $0.77(0.03)$ \\
\hline IV (highest) & $21-24$ & 68 & $5.63(0.12)$ & $0.90(0.06)$ & $1.85(0.05)$ & $3.31(0.13)$ & $2.07(0.11)$ & $0.71(0.03)$ \\
\hline Difference* & & & 0.51 & 0.20 & 0.27 & 0.51 & 0.37 & 0.11 \\
\hline \multicolumn{3}{|c|}{$\begin{array}{l}\text { pt } \\
\text { Adjusted for age and lifestyle factors:: }\end{array}$} & 0.03 & 0.27 & 0.0004 & 0.02 & 0.02 & 0.02 \\
\hline \multicolumn{3}{|c|}{ pt } & 0.06 & 0.31 & 0.002 & 0.06 & 0.10 & 0.07 \\
\hline
\end{tabular}

* Difference $=$ difference in mean values between the lowest and the highest quartile of decision latitude.

$\dagger p=p$ value for the effect of decision latitude on lipid variables.

$¥$ Lifestyle factors include smoking, physical exercise, alcohol consumption, total energy, total fat, carbohydrate, protein intake, body mass index and waist/hip ratio.

Associations with cholesterol, triglycerides and apolipoprotein B/apolipoprotein A1 ratio did not reach statistical significance (table 3 ).

\section{LIPID PROFILE IN RELATION TO DECISION LATITUDE}

There was a curvilinear effect of decision latitude on cholesterol $(p<0.03)$, on HDL $(p<0.0004)$, on LDL/HDL ratio $(p=0.02)$, and on the apolipoprotein B/apolipoprotein A1 ratio $(p=0.02)$, after adjusting for age. The highest levels of HDL were observed in the third quartile, while the most elevated levels of LDL/HDL ratio and apolipoprotein B/apolipoprotein Al ratio were found in the second quartile. Significant differences for HDL across quartiles of decision latitude persisted after adjusting for age, menopause and lifestyle factors $(p<0.01)$ (table 4$)$.

A linear effect of decision latitude was observed for cholesterol/HDL ratio $(p=0.02)$, while the association with triglycerides was not significant in the age adjusted model (table 4). High decision latitude at work was significantly associated with high income $(p=0.002)$, high educational level $(p<0.0001)$, and larger houses or apartments $(\mathrm{p}=0.05)$.

LIPID PROFILE IN RELATION TO THE NUMBER OF ROOMS IN THE HOUSE OR APARTMENT

After controlling for age and the number of persons in the household, a curvilinear effect of number of rooms in the house or apartment was observed on triglycerides $(p=0.05)$ and on HDL $(p=0.01)$. The lowest levels of HDL and most elevated levels of triglycerides were observed in the second quartile.

A marginal linear effect was observed on the cholesterol/HDL ratio $(p=0.05)$, the LDL HDL ratio $(p=0.13)$ and on the apolipoprotein $B$ /apolipoprotein $A 1$ ratio $(p=0.10)$.

The effect on cholesterol (after adjusting for age) was non-significant (table 5). Marital status was significantly associated with the number of rooms in the house or apartment $(p<0.0001)$. Single women had smaller houses/ apartments (2.6 (1.1) rooms) than women who were cohabiting (4.5 (1.7) rooms). In spite of 
Table 5 Effect of number of rooms on lipid profile. Mean (SEM) lipid values

\begin{tabular}{|c|c|c|c|c|c|c|c|c|}
\hline $\begin{array}{l}\text { No of rooms (quartiles) } \\
\text { (quartiles) }\end{array}$ & $\begin{array}{l}\text { Range in no } \\
\text { of rooms }\end{array}$ & No & $\begin{array}{l}\text { Cholesterol } \\
\text { (mmolll) }\end{array}$ & $\begin{array}{l}\text { Triglycerides } \\
\text { (mmolll) }\end{array}$ & $\begin{array}{l}H D L \\
(\mathrm{mmol} / \mathrm{l})\end{array}$ & $\begin{array}{l}\text { Cholesterol/ } \\
H D L\end{array}$ & $L D L / H D L$ & $\begin{array}{l}\text { Apolipoprotein } B / \\
\text { apolipoprotein } A 1\end{array}$ \\
\hline \multicolumn{9}{|c|}{ Adjusted for age and no of persons in household: } \\
\hline I (lowest) & $1-2.5$ & 62 & $6.11(0.10)$ & $1.10(0.07)$ & $1.70(0.06)$ & $3.94(0.13)$ & $2.57(0.11)$ & $0.86(0.03)$ \\
\hline II & 3 & 75 & $6.09(0.13)$ & $1.16(0.06)$ & $1.67(0.05)$ & $3.75(0.16)$ & $2.42(0.13)$ & $0.81(0.03)$ \\
\hline III & 4 & 52 & $6.02(0.11)$ & $1.08(0.07)$ & $1.78(0.06)$ & $3.57(0.14)$ & $2.27(0.12)$ & $0.77(0.03)$ \\
\hline IV (highest) & $5-11$ & 98 & $5.94(0.14)$ & $0.93(0.05)$ & $1.86(0.04)$ & $3.43(0.11)$ & $2.16(0.10)$ & $0.76(0.03)$ \\
\hline Difference* & & & 0.17 & 0.08 & 0.16 & 0.51 & 0.41 & 0.10 \\
\hline \multirow{2}{*}{\multicolumn{3}{|c|}{$\begin{array}{l}\mathrm{p} \dagger \\
\text { Adjusted for age and lifestyle factorsł: }\end{array}$}} & 0.73 & 0.05 & 0.01 & 0.05 & 0.13 & 0.10 \\
\hline & \multicolumn{2}{|c|}{ pt } & 0.75 & 0.33 & 0.14 & 0.26 & 0.43 & 0.18 \\
\hline
\end{tabular}

* Difference $=$ difference in mean values between the lowest and the highest quartile of number of rooms.

$t p=p$ value for the effect of number of rooms on lipid variables.

$\ddagger$ Lifestyle factors include smoking, physical exercise, alcohol consumption, total energy, total fat, carbohydrate, protein intake, body mass index and waist/hip ratio.

Table 6 Effect of annual income on lipid profile. Mean (SEM) lipid values

\begin{tabular}{|c|c|c|c|c|c|c|c|c|}
\hline $\begin{array}{l}\text { Income level } \\
\text { quartiles }\end{array}$ & $\begin{array}{l}\text { Range in Swedish } \\
\text { crowns** }\end{array}$ & No & $\begin{array}{l}\text { Cholesterol } \\
(\mathrm{mmol} / \mathrm{l})\end{array}$ & $\begin{array}{l}\text { Triglycerides } \\
\text { (mmolll) }\end{array}$ & $\begin{array}{l}\text { HDL } \\
(\mathrm{mmol} / \mathrm{l})\end{array}$ & $\begin{array}{l}\text { Cholesterol/ } \\
H D L\end{array}$ & $L D L / H D L$ & $\begin{array}{l}\text { Apolipoprotein B/ } \\
\text { apolipoprotein A1 }\end{array}$ \\
\hline \multicolumn{9}{|c|}{ Adjusted for age: } \\
\hline I (lowest) & $8400-110650$ & 71 & $6.12(0.11)$ & $1.10(0.06)$ & $1.68(0.05)$ & $3.79(0.14)$ & $2.42(0.12)$ & $0.80(0.03)$ \\
\hline II & $110651-151100$ & 71 & $6.24(0.11)$ & $1.11(0.06)$ & $1.74(0.05)$ & $3.80(0.13)$ & $2.46(0.11)$ & $0.84(0.03)$ \\
\hline III & $151101-196450$ & 71 & $6.02(0.11)$ & $1.04(0.06)$ & $1.72(0.05)$ & $3.69(0.13)$ & $2.38(0.12)$ & $0.81(0.03)$ \\
\hline IV (highest) & $196451-504900$ & 71 & $5.86(0.12)$ & $0.98(0.06)$ & $1.90(0.05)$ & $3.37(0.14)$ & $2.12(0.12)$ & $0.75(0.03)$ \\
\hline \multirow{2}{*}{\multicolumn{3}{|c|}{ Difference* }} & 0.32 & 0.12 & 0.22 & 0.42 & 0.30 & 0.05 \\
\hline & \multicolumn{2}{|c|}{ Adjusted for a } & 0.10 & 0.45 & 0.01 & 0.09 & 0.14 & 0.23 \\
\hline \multicolumn{3}{|l|}{ pt } & 0.22 & 0.60 & 0.04 & 0.45 & 0.45 & 0.55 \\
\hline
\end{tabular}

* Difference $=$ difference in mean values between the lowest and the highest quartile of annual income.

$t p=p$ value for the effect of income level on lipid variables.

$\ddagger$ Lifestyle factors include smoking, physical exercise, alcohol consumption, total energy, total fat, carbohydrate, protein intake body mass index and waist/hip ratio. ** $100 £$ sterling $=1000$ Swedish crowns; $100 \$$ US $=650$ Swedish crowns (1996 exchange rate).

this association, controlling for marital status did not alter the associations observed in the age adjusted model. However, after adjusting for age and all lifestyle factors, the effect of number of rooms on lipid variables disappeared.

\section{LIPID PROFILE IN RELATION TO INCOME}

Age adjusted significant differences across quartiles of income were observed for HDL $(p=0.01)$. Women in the upper quartile had higher HDL levels than women in the lower quartiles of income. These associations persisted after adjustment for age, lifestyle factors, and dietary habits $(p=0.04)$ (table 6). Adjusting for marital status did not alter the income-HDL association.

Cholesterol, triglycerides, cholesterol/HDL ratio, LDL/HDL ratio, and apolipoprotein $\mathrm{B} /$ apolipoprotein A1 ratio did not show significant associations with income, although, there was a tendency towards an unhealthy lipid profile for women in the lower quartiles (table 6).

\section{CORRECTION FOR MULTIPLE COMPARISONS}

After simultaneous adjustment for other SES measures (educational level, annual income, occupation and housing condition), in the multivariable regression model (adjusted for age, menopausal status and all lifestyle factors) significant effects on HDL were observed for decision latitude $(p<0.001)$, educational level $(p=0.05)$, and annual income $(p=0.06)$. The effects of occupation and housing condition on HDL levels did not reach statistical significance.

\section{Discussion}

The observations described in this report, indicate that healthy Swedish women with low decision latitude at work, low annual income, low educational level, smaller houses or apartments, and blue collar jobs have an unhealthy lipid profile.

Of the lipid variables, low HDL levels were most consistently associated with low SES. Of the five measures of SES used, decision latitude, educational level, and annual income had the strongest associations with lipid profile. These associations were independent of age, menopausal status, smoking, sedentary lifestyle, alcohol consumption, obesity, excess abdominal fat and unhealthy dietary habits.

Decision latitude at work was the best SES predictor of HDL levels in healthy middle aged Swedish women, after simultaneous adjustment for other SES measures and lifestyle factors.

Several large scale population studies have found an association between lipid variables and social class in both men and women. The most important studies are the Scottish heart health study, ${ }^{10}$ the Lipid Research Clinics program prevalence study, ${ }^{11}$ the Framingham offspring study, ${ }^{12}$ the Minnesota heart survey, ${ }^{13}$ the Tromsö heart study, ${ }^{14}$ and the Australian National Heart Foundation risk factor prevalence study. ${ }^{29}$ The association between occupation and the cholesterol/HDL and LDL HDL ratios observed in this report is similar to the findings from the Scottish heart health study. ${ }^{10}$

The association between education and HDL found in the present study is in accordance with the findings from three other 
studies; the Lipid Research Clinics program prevalence study, ${ }^{11}$ the Framingham offspring study, ${ }^{12}$ and the Australian study. ${ }^{29}$

The SES-cholesterol association in women is less consistent than that in men. Some studies have found a social gradient for cholesterol in women, ${ }^{131418}$ while others have not found any gradient. ${ }^{12}$ In the present report, only decision latitude showed significant age adjusted association with cholesterol.

The association (after adjustment for age, number of persons in household, and marital status) between the number of rooms in the house/apartment and the lipid profile, found in this study, is similar to the results from the Scottish heart health study. ${ }^{10}$ Woodward et al used housing tenure (owning or renting), as one of the measures of SES and found univariate associations between housing tenure and the lipid profile.

The association between low income and low HDL levels, is contradictory to the results from the Minnesota heart survey and the Scottish heart health study. The authors did not find any associations between income and lipid variables. Social norms and cultural differences may explain this contradiction.

The curvilinear association between SES measures and lipid variables observed in this report is consistent with a non-linear relationship observed in mortality rates across occupational levels in various countries. ${ }^{30}$ The authors reported that in most countries, mortality rates in skilled manual workers were lower than those of lower level employees.

With the exception of the Minnesota study ${ }^{13}$ and the Scottish heart health study, ${ }^{10}$ the studies mentioned above, ${ }^{11121429}$ used education only as a measure of social class and they did not include the whole lipid profile, but only total cholesterol and HDL.

In summary, these studies did not capture the full lipid profile nor did they examine the full social gradient as conceptualised by Max Weber. ${ }^{15}$ Perhaps most importantly, the "power" dimension of social class was not addressed. It is interesting to note that among the SES indicators examined in this report, the power dimension (decision latitude at work) was found to have the strongest independent effect on the lipid profile.

The fact that education, occupational grade, decision latitude, annual income, and the type of housing were not highly intercorrelated $(r=$ 0.11 to 0.43 ), seems to confirm Weber's view that each measure describes a different aspect of SES. ${ }^{15}$ Other studies have demonstrated intercorrelations of similar magnitude. ${ }^{31}$

Our findings suggest that occupational grade alone does not appropriately characterise women's social status. Men and women often have different work tasks even when they work in the same occupations. There is a need to identify occupational grade measures which take the real status of women's work into account. Therefore decision latitude at work may be used as an indicator of the power and control which women experience in their occupations.

The fact that neither lifestyle factors nor the inclusion of other SES measures was able to "explain away" the HDL-control association, requires further consideration.

Several studies, both in animals and in humans, have shown that mental stress is often associated with hyperlipidaemia. ${ }^{323}$ The mechanisms of these effects are insufficiently known, but possible pathways linking loss of control to mental stress and metabolic changes have been suggested. There is evidence that loss of control, induced helplessness, and depression are associated with endocrine responses including increased circulating cortisol levels. ${ }^{34}$

Cortisol may act as an insulin antagonist, increasing insulin resistance at the cellular level. The consequences of increased insulin resistance include increased levels of circulating triglycerides and a decline in HDL.

There are rather few studies of lipid profile in relation to stressful conditions at work. One early study which clearly examined work impacts, observed significant temporary increases in the serum cholesterol concentration for income tax accountants before the April 15 income tax dead line, which is a period of high job stress. ${ }^{35}$

In other studies of acutely stressful situations, stress experienced over weeks by soldiers, ${ }^{36} 37$ by airline pilots, ${ }^{38}$ and submarine crews, ${ }^{39}$ have been found to raise plasma lipids. Furthermore, Siegrist et al, showed that adverse long lasting chronic job stress may increase the ratio of LDL/HDL. ${ }^{40}$

One intervention study focused on the reduction of psychosocial stressors at work and reported a concomitant increase in serum apolipoprotein A1 (used as a proxy measure of HDL) which was not explained by changes in lifestyle factors (dietary habits, exercise and smoking habits). The intervention period was eight months, and included work organisation changes, particularly increased autonomy and control over decisions, and improved supervisor social supports. ${ }^{41}$

\section{CONCLUSION}

The finding that low decision latitude at work was the strongest SES predictor of a poor lipid profile in middle aged Swedish women, independent of age, educational level, occupation, annual income, housing conditions, menopausal status, lifestyle factors, obesity, abdominal fat, and dietary habits, confirms the need to consider "power" as a major dimension defining women's socioeconomic status. It is suggested that these findings may provide part of the explanation for the social gradient in CHD among Swedish women. ${ }^{42}$

The authors are grateful to Mosér V, Blom M, Eriksson I, Rosenberg $U$, Eriksson $M$ and Högbom $M$ for their contribution to data collection

Funding: this work was supported by grant no HL45785 from the US National Institutes of Health, by grant no B93-19X10407 from the Swedish Medical Research Council and a gran from the Swedish Labour Market Insurance Company. Conflicts of interest: none.

1 Antonovsky A. Social class and the major cardiovascular diseases. F Chron Dis 1968;21:65-106.

2 Hinkle LE, Whitney LH, Lehman EW et al. Occupation education and coronary heart disease: risk if influenced more by education and background than by occupational experiences in the Bell system. Science 1968; 161:238-46. 
3 Holme I, Helgeland A, Hjermann I, Leren P, Lund-Larsen PG. Four year mortality by some socioeconomic in dicators: the Oslo Study. F Epidemiol Community Healt 1980;34:48-52.

4 Rose G, Marmot MG. Social class and coronary hear disease. Br Heart $\mathcal{F} 1981 ; 45: 13-19$.

5 Liu K, Cedres LB, Stamler J, et al. Relationship of education to major risk factors and death from coronary heart disease, cardiovascular diseases and all causes; findings of three Chicago Epidemiologic Studies. Circulation 1982;66: 1308-14.

6 Salonen JT. Socioeconomic status and risk of cancer, cerebral stroke and death due to coronary heart disease and any disease: a longitudinal study in eastern Finland. I Epidemiol Community Health 1982;36:294-97.

7 Vàgero $\mathrm{D}$, Lundberg $\mathrm{O}$., Healthy inqualities in Britain and Swe D, Lundberg O., Healthy in

8 Dennis BH, Zhukovsky GS, Shestov DB, et al. The association of education with coronary heart disease mortality in the USSR Lipid research Clinics Study. Int $\mathcal{f}$ Epidemiol 1993;22:420-27.

9 Diez-Roux AV, Nieto FJ, Tyroler HA, Crum LD, Szklo M Social inequalities and atherosclerosis. The atherosclerosis risk in communities study. Am $\mathcal{F}$ Epidemiol 1995;141: 960-72.

10 Woodward M, Shewry MC, Smith WC, Tunstall-Pedoe H. Social status and coronary heart disease: results from the Scottish Heart Health Study. Prev Med 1992;21(1): $136-48$

11 Heiss G, Haskell W, Mowery R, Cirqui MH, Brockway M, Tyroler HA. Plasma high density lipoprotein cholesterol and socio-economic status-The Lipid Research Clinics program prevalence study. Circulation 1980;62 (Suppl IV) : program

12 Garrison RJ, Gold RS, Wilson PW, Kannel WB., Educational attainment and coronary heart disease risk: the Framingham Offspring Study. Prev Med 1993;22(1):54-64.

13 Leupker RV, Rosamond WD, Murphy R, Sprafka JM, Folsom AR, McGovern PG, Blackburn H., Socioeconomic status and coronary heart disease risk factor trends. Th Minnesota heart survey. Circulation Nov 1993;88:2172-9.

14 Jacobsen BK, Thelle DS. Risk factors of coronary heart disease and level of education. The Tromsö heart study. Am f Epidemiol 1988;127:923-32.

15 Weber M, Class, status and party. In: Gerth $H$, Mills CW, eds. From Max Weber: Essays in sociology NY: Oxford University Press, 1946.

16 Statistics Sweden, The thirty largest occupations 1990. In: Census, 1990. Stockholm: Statistics Sweden. 1990

17 Orth-Gomér K, Mittleman M, Schenck-Gustafsson K, et al. Lipoprotein(a) as determinant of coronary heart disease al. Lipoprotein(a) as determinant of coronary heart
in younger women., Circulation 1997;95:329-334.

18 Romelsjö A, Hasin D, Hilton $M$, et al. The relationship between stressful working conditions and high alcoho consumption and severe alcohol problems in an urba general population. $B r \mathcal{F}$ Addiction 1992; 87:1173-83.

19 Statistical Central Bureau of Sweden. Pà tal om kvinnor och män (On men and women) 1990. In: Lathund om fämställdhet, 1990

20 Karasek R, Baker D, Marxer F, Ahlbom A, Theorell T., Job decision latitude, job demands, and cardiovascular disease. A prospective study of Swedish men. Am f Public Health 1981;71:694-705.

21 Riepponen P, Marniemi J, Rautaoja T. Immunoturbidimetric determination of apolipoprotein A-1 and B in serum. Scand $¥$ Clin Lab Invest 1987;47:739.
22 Jungner I, Walldius G, Holme I, Steiner E. Apolipoprotein $B$ and A-1 in relation to serum cholesterol and triglyceride in 43000 Swedish males and females. Int 7 Clin Lab Res 1992;21:247-55.

23 Glueck CJ, Taylor HL, Jacobs D, Morrison JA, Beaglehole R. Plasma high-density lipoprotein: association with measures of body mass. The Lipid Research Clinics program prevalence study. Circulation 1980;62 (Suppl IV): 62-69.

24 Willet WC, Sampson L, Stampfer Jet al. Reproducibility and validity of semi quantitative food frequency questionnaire. Am ₹ Epidemiol 1995;122:51-65.

25 Swedish Food Administration. Weight tables for foods and dishes. Uppsala, Swedish Food Administration, 1988.

26 Bergström L. Food data base PC Version. 1992. Swedish Food Administration Reports 1992; No 14.

27 Myrhed M. Alcohol consumption in relation to factors associated with ischemic heart disease. A co-twin control study. Acta Med Scand 1974:567 (Suppl).

28 SAS Institute. FMP Statistics for the Apple Macintosh, version 3.1. Cary, NC. SAS Institute Inc, 1994.

29 Simons LA, Simons J, Magnus P, Bennett SA. Educationa level and coronary risk factors in Australians. Med $\mathcal{f}$ Aust 1986;145:446-50.

30 Kunst AE, Mackenbach JP., International variation in the size of mortality differences associated with occupational status. Int $\mathcal{F}$ Epidemiol 1984;23(4):742-750.

31 Kamieniecki S, O'Brien R., Are social class measures interchangeable? Fournal of Political Behaviour 1984:6:41-59.

32 Clarkson TB Adams MR Kaplon JR, Koritnik DR. Psychosocial and reproductive influences on plasma lipids, lipoproteins, and atherosclerosis in non human primates. $f$ proteins, and atherosclerosis

33 Dimsdale JE, Herd JA. Variability of plasma lipids in response to emotional arousal. Psychosom Med 1982;44. sponse to

34 Brindley DN, McCann BS, Niaura R, Stoney CM, Suarez EC. Stress and lipoprotein metabolism: modulators and mechanisms. Metabolism 1993;42 (2 suppl 1):3-15.

35 Friedman M, Rosenman RH, Carroll V. Changes in the serum cholesterol and blood clotting time in men subjected to cyclic variation of occupational stress. Circulation 1958; 17:852-61.

36 Arguellos A, Martinez M, Hoffman C, Ortiz G, Checkherdemian $M$. Corticoadrenal over activity and hypelipidemia in prolonged emotional stress. Hormones 1972 ; 3:167-74.

37 Rahe R, Rubin R, Arthur R, Clark B. Serum uric acid and cholesterol variability. $\mathcal{F A M A} 1968 ; 206: 2875-80$.

38 Carruthers $M$, Taggart $P$. Vagotonicity of violence: Biochemical and cardiac responses to violent films and telechemical and cardiac responses to violent

39 Campbell D, Rahe R. Serum uric acid and cholesterol variability for men aboard a Polaris submarine. Mil Med 1974;139:462-65.

40 Siegrist J, Matschinger M, Cremer P, Seidel D. Atherogenic risk in men suffering from occupational stress. Atherosclerosis 1988;69:211-18.

41 Orth-Gomér K, Eriksson I, Moser V, Theorell T, Fredlund P. Lipid lowering through work stress reduction. International fournal of Behavioral Medicine 1994;1(3):204-14.

42 Orth-Gomér K, Schenck-Gustafsson K, Eriksson I, Högbom M, Wamala PS, Blom M, Moser V, Belkic K. Psykosociala riskfaktorer för kranskärlssjukdom hos kvinn (Psychosocial risk factors for coronary heart disease in women). Stress Research Reports 1995;255. 